\title{
Language and Culture
}

\author{
Orly Kayam ${ }^{1^{*}}$ \\ ${ }^{1}$ Wingate Academic College, Netanya, Israel \\ * Orly Kayam, E-mail: orlyka@wincol.ac.il
}

\begin{abstract}
The study focuses on Ethiopian Jewish women's struggles with language usage and social adaptation. The study aims to (a) evaluate the importance of knowledge and usage of Amharic in their daily lives, (b) evaluate the importance of knowledge and usage of Hebrew in their daily lives and (c) identify the differences in Israeli and Ethiopian Jewish cultures. The study was based on data collected and analyzed from a questionnaire that was distributed to a class of Ethiopian Jewish women who study English at a school in Netanya, Israel. The findings showed that while all of the participants speak Amharic, there are differences in literacy in Amharic among them. All of them have difficulties in Hebrew, but see Hebrew as the vehicle for upward mobility within Israeli society. They view Israeli culture as one that is lacking in politeness, respect and dignity, which is very much part of the fabric of the Ethiopian Jewish lifestyle. There is also a strong desire to preserve the past by preserving their language. This study promotes a new dimension to the study of Ethiopian Jewish women (Kayam \& Hirsch, in press) in that it adds to the study of language acquisition in the immigrant setting.
\end{abstract}

\section{Keywords}

Amharic, Hebrew, migration, adaptation, economic stability, literacy

\section{Introduction}

The purpose of this study is to research the phenomenon of Ethiopian Jewish women in Israel, who are striving to preserve their culture and language on the one hand while adapting to Israeli culture and the Hebrew language on the other. This paper is part of a series of research papers dealing with the integration of Ethiopian Jewish women in Netanya, Israel with respect to language barriers (Kayam, 2014). Fenster (1998) explains that much of the financial burden has fallen on the shoulders of these women, who despite the fact that their Hebrew fluency lagged behind that of men, have succeeded in advancing in employment to a greater extent than was expected of them. This research attempts to understand these women's attitudes towards acquiring a new language and adapting to a new culture in the context of migration. The goal of this present study is to document this very unique and special situation with a focus on their daily language experiences. 


\subsection{Theoretical Background}

According to surveys conducted by Benton, Noam and Levy (1994), the most prevalent concern among Ethiopian Jews in Israel is their economic situation. For the most part, Israeli government policies that aim to encourage women to work outside the home in occupations other than unskilled jobs have not succeeded (Kaplan \& Salamon, 2004). This is somewhat akin to the traditional role that women played in Ethiopia as being in charge of the private domain of the household (Fenster, 1998). There have been attempts to change this situation through Social Security and other government programs that are aimed at giving women job opportunities outside of those that they have held traditionally. However, the overall statistics present the economic difficulties that most Ethiopian Jewish households face. According to the Israel Association of Ethiopian Jewry (IAEJ), "more than $72 \%$ of Ethiopian immigrant children grow up in families that are living below the poverty line established by the Israeli government" and that "less than $40 \%$ of Ethiopian families in Israel with children have a breadwinner" (Berhanu, 2005, p. 67). A third of the Ethiopian Jewish families are single-parent families (Weil, 2004). In addition, Kaplan and Salamon (2004) add that even when they work more hours or take on extra work, Ethiopian families have great financial difficulties.

As Ethiopian Jewish women in Israel take on more economic responsibility, their traditional role as being in charge of the private domain of the home is evolving into encompassing much more than in the past. Kaplan and Salamon (2004) explain that girls and young women have a wider range of choices as to their "education, age of marriage, the number and the timing of their children" (p. 136). Women enjoy more freedom in and out of the family and there is resentment on the part of the Ethiopian Jewish men at the loss of their status as the head of the house and as being the one in the past who managed the family finances. Thus, due to the changes in the Ethiopian Jewish experience in Israel, the home is the place where a reformulation of the traditional roles of the family is taking place and may continue into the next generation (Westheimer \& Kaplan, 1992; Salamon, 2004). The Ethiopian Jewish community has a higher divorce rate than that of the rest of the population and this is mainly due to the lower status relegated to the men. In Ethiopia, masculinity was venerated and femininity was degraded. The symbol of masculinity was the staff which every man carried and the symbol of femininity was blood. Men were praised in Amharic expressions and women were disgraced (Weil, 2004).

In my previous paper, Language Barriers among Ethiopian Women in Netanya, Israel, I touched on the acculturation problems and language barriers that the Ethiopian Jews experienced and I am elaborating on them in this paper. When the Ethiopian Jews moved to Israel, they found the Israeli culture to be enormously dissimilar to their own (Tannenbaum, 2009). Much of what they had known, their behavioral patterns and skills were not relevant anymore. They had to learn a whole new code of behavior in order to acclimate themselves in their new environment (Berhanu, 2005). For most of them, the adjustment process proved to be extremely arduous (Fenster, 1998).

Ethiopian Jewish culture was passed down to the younger generation "through ritual and word of Published by SCHOLINK INC. 
mouth” (Kaplan \& Salamon, 2004, p. 137). According to Tannenbaum (2009), Ethiopian Jews use language as a way to communicate and protect the values that are important to them such as "family relations and respect for elders” (p. 977). Their fears are that unless there is a major effort to preserve their language, they will lose their traditions of the past. Kaplan and Salamon (2004) point out that Ethiopian Jews spoke Amharic and those who lived in the Northern provinces spoke Tyrinnga. Ge'ez, an ancient Semitic language, was the language used to pray in and their Bible and other holy books were written in that language. Most people in the community were illiterate. They had no contact with Hebrew prior to their immigration.

Today, Ethiopian Jews in Israel are surrounded by Hebrew as a spoken language and also one used to read and write in. Despite efforts to teach them Hebrew, many adults in the community have not acquired Hebrew. Concomitant with this phenomenon is the position that many youngsters who were either born in Israel or came to Israel when they were young children find themselves in. They can understand either spoken language to some extent and can speak the language but cannot read or write Amharic or Tyrinnga. There are only a few programs currently that endeavor to teach Amharic to Ethiopian Jewish children. This means that today Hebrew is the language that is read and written in. Amharic remains the oral language. Broadcasts on the radio in Amharic or Tyrinnga are listened to widely and as of May, 1997, there is a half-hour weekly show in Amharic on television.

In the context of migration, the Ethiopian Jewish community is undergoing many changes. Amongst them is the transformation of women from being considered weaker than men, to becoming more powerful than they were in the past as they emerge from their private domain and find employment in the general Israeli society (Weil, 2004).

\section{Methodology}

A questionnaire was developed and distributed to Ethiopian Jewish women aged 33 to 52 years old, with the mean age being 45, in a municipality sponsored English language class. These women are learning English as part of a program aimed at giving them the equivalent of an elementary school education. The program consists of five subjects: Reading Comprehension in Hebrew, Bible Studies, English, Mathematics and Behavioral Science. After completion of the program and with the diploma that they will receive, they will be able to find employment that demands an eighth grade education. In addition, they will be qualified to attend specialized courses in their fields of expertise. After completion of this program they have the option of attaining the equivalent of 10 years of education or of 12 years of education. The municipality provides these programs as well.

Twelve women filled out the questionnaire. All of the women who participated in this research were born in Ethiopia and immigrated to Israel between the years 1990 to 2001. Their first language was Amharic. Hebrew has been acquired and in some cases has surpassed Amharic. Such is the case of reading a newspaper. Most said they read the newspaper in Hebrew. Only one of the participants claimed to read the newspaper in Amharic as well.

Published by SCHOLINK INC. 
The questionnaire consists of four parts. Part A consists of demographic questions about the participants themselves with regard to their age, when they arrived in Israel and questions about their languages. Part B asks the participants to self-report on a scale of 1 to 5 with one being very poorly and 5 being very well, how well they speak, understand, read and write Amharic, Hebrew and English. Part $\mathrm{C}$ instructs the participants to put an $\mathrm{X}$ next to the situations where they speak Amharic, to put a V next to situations where they speak Hebrew, and to leave a blank next to situations that are irrelevant to their lives. The situations are: talking to a cashier in the supermarket, talking to their parents, with their spouses, their children with their spouses and children in a public place, with their neighbors, at work, in the bank and on the beach. Part D consists of 15 open-ended questions such as: In your opinion, to what extent is the Ethiopian Jewish culture and the traditions perceived in Israeli society? In which situations do you speak Amharic and in which situations do you speak Hebrew? How important is the English language in your lives? And what are the most obvious differences between the Ethiopian culture and the Israeli one?

This current study expands on the case study in my book "Family Language Policy: A Glimpse into the Israeli Immigrant Experience using a Linguistic Lens” as it looks at language and culture through the experiences of twelve Ethiopian Jewish women. The present study examines whether the participants experienced the same difficulties as did Malka, the participant in the previous study, or others. These difficulties translated into three research questions as follows:

1) How important is knowledge and usage of Amharic for Ethiopian Jewish women in their daily lives?

2) How important is knowledge and usage of Hebrew for Ethiopian Jewish women in their daily lives?

3) What are the differences that Ethiopian Jewish women find in Israeli culture as compared to Ethiopian Jewish culture and traditions?

\section{Results}

3.1 How Important is Knowledge and Usage of Amharic for Ethiopian Jewish Women in Their Daily Lives?

According to their self-reported answers in the questionnaire, all of them claim that they speak Amharic. However, only six women reported that they speak, understand, read and write Amharic well. The others claimed only partial knowledge. All of them use Amharic to speak to their parents and their brothers and sisters. All of them speak Amharic with their spouses, at home and in the public space. They consistently speak Amharic with their childhood friends and with their distant relatives. Children are mostly spoken to in Hebrew, but they hear the language in the home. One participant explained that she speaks to her children in Amharic, but they answer her in Hebrew. All of the participants agreed that it is important to preserve Amharic, and two participants elaborated on this fact by connecting knowledge of the language to knowledge of their roots, something that is very personal. They want their children to know their heritage and not forget it. One of the women stated that their names in Amharic are their identities, and that the names have deep meanings for them. They want to preserve 
these names and not take on Hebrew names. In contrast, another participant explained that Israelis have a difficult time while attempting to pronounce Ethiopian names. Her solution was maybe they should have two names, one in Amharic and one in Hebrew.

3.2 How Important is Knowledge and Usage of Hebrew for Ethiopian Jewish Women in Their Daily Lives?

None of the participants claim to have excellent knowledge of Hebrew. However, all of them claimed that their understanding of Hebrew and their speaking in Hebrew is better than their reading and their writing in Hebrew. One of the older women has never acquired Hebrew and could not write the answers to the questionnaire. One woman explained that Hebrew is very important for her and for her children because it is the language in which all of them could improve their lives and it's the language of the country that they are residing in. Another woman said that she wants her children to have another

language, aside from Amharic. Hebrew is used by all of the participants with their children at home and in the public space. Hebrew is used consistently at school, at work, at the supermarket, in the bank and on the beach. While most speak Hebrew with their neighbors, two of the respondents said that they also speak Amharic with their neighbors as well.

3.3 What are the Differences That Ethiopian Jewish Women Find in Israeli Culture as Compared to Ethiopian Jewish Culture and Traditions?

Three of the participants explained that Ethiopian Jewish culture contains an element of respect, dignity and politeness that is missing in Israeli culture. They felt that Israelis could learn how to behave in a more dignified way from the Ethiopian lifestyle. They attested to the fact that in Ethiopian culture, much respect is given to the elders among them, to assistance that they give one another when the need arises, to the unity in the families and to observing Sabbath. When they alluded to the differences between Ethiopian culture and Israeli culture, some expressed the difference due to the color of their skin, which sets them apart. Others referred to the different foods associated with the two cultures and to the languages. One participant explained that in Ethiopia, women were relegated to the home, while men were responsible for their farms and for providing food on the table for the year. They had to protect their farms from thieves who would steal the food and animals that would ruin their farms. Men and women were very involved in the basics of life. This participant believed that in Israel, in contrast to the life in Ethiopia, there is a supreme being that watches and provides us with the enormous variety of foods and goods that are so abundant here. Only one participant felt that she is equal to Israeli women. Four other participants stated that even after living in Israel for many years, they still feel completely different from Israelis. One of these women has experienced language discrimination due to her Ethiopian accent in Hebrew. The second one explained that her culture is completely different from the Israeli culture. The third one claimed that the Ethiopian Jewish way of educating their families and their learning styles are completely different from the Israeli educational methods. The fourth one blamed the Israeli public for relating to her as an Ethiopian who still does not know anything about Israeli culture. 


\section{Discussion}

The goal of this study was to examine the situation of Ethiopian Jewish women who are trying to preserve their culture and their language while at the same time trying to advance themselves and their families educationally and economically in Israeli society. By focusing on these women this study attempted to expose the specific difficulties that they have as they go about their daily lives in Israel.

From the findings we see the desire to and the difficulties in preserving Amharic for the next generation. According to Tannenbaum (2009), for Ethiopian Jews, their language is their link to their traditions and to their past and in Israel their fear is that it might disappear. The findings also confirmed what Kaplan and Salamon (2004) pointed out that at this time we find more Ethiopian Jews who can read and write in Hebrew, but cannot do the same thing in Amharic. Finally, the findings show that the two cultures, the Ethiopian Jewish one and the Israeli culture are, as Wagaw (1993) explains, "dissimilar in language, culture, religious practice, education, technology, race and class” (p. 12). We can thus understand why Ethiopian Jewish women, who even after many years in Israel, feel the difference in cultures so strongly.

It is the hope of this study that through understanding the differences and difficulties the Ethiopian Jews have in Israeli society that there will be a greater effort on the part of that society to accept and assist them as best they can.

This study includes some limitations as it was based on subjective self-reported material. It is quite possible that a study that was measured objectively or one whereby participants were observed in their daily interactions in Amharic and in Hebrew would have resulted in different conclusions. An additional limitation is that the study was conducted using a relatively small sample which was not totally random. Future research might include a larger sample base and the participants would be chosen at random.

\section{Conclusion}

It is recommended that the findings be used on a practical level involving agencies that deal with Ethiopian Jewish immigrants and by companies who are interested in extending their services to this community. These companies and agencies should make the effort to assist the Amharic speaker who wishes to speak on the telephone with a representative of that company or agency. There should be an option for Amharic and the company should ascertain that their customer service assistants can converse in Amharic.

The author recommends using the findings to heighten awareness of the people behind the language (Amharic) and culture and hence, to make an argument in support of a wider inclusive policy for services and rights to all Ethiopian Jewish immigrants in Israel, but especially to the women among them. Hopefully, studies such as the present one can be applied to help empower these women in situations where they encounter difficulties in employment and in acceptance into Israeli society. 


\section{References}

Berhanu, G. (2005). Normality, Deviance, Identity, Cultural Tracking \& School Achievement: The Case of Ethiopian Jews in Israel. Scandinavian Journal of Educational Research, 49(1), 51-82.

Blustein, M. (2006). Adherence to Yemenite Tradition and the Preservation of the Yemenite Accent in Hebrew Speech (M.A. studies). Tel-Aviv University, Tel-Aviv, Israel.

Fenster, T. (1998). Ethnicity, Citizenship, Planning \& Gender: The case of Ethiopian immigrant women in Israel. Gender, Place and Culture, 5(2), 179, 181.

Kaplan, S., \& Salamon, H. (2004). Ethiopian Jews in Israel: A Part of the People or Apart from the People? In C. Isaac, \& U. Rebhun (Eds.), Jews in Israel: Contemporary social \& cultural patterns (pp. 118-144).

Kayam, O., \& Hirsch, T. (2014). Family Language Policy: A Glimpse into the Israeli Immigrant Experience using a Linguistic Lens (In Press).

Kayam, O. (2013). Heritage Language Maintenance among Native English Speakers Living in Israel. Journal of Sociological Research, 4(2), 308-317.

Tannenbaum, M. (2009). What's in a Language? Language as a Core Value of Minorities in Israel. Journal of Ethnic \& Migration Studies, 35(6), 995-997.

Wagaw, T. G. (1993). For our soul: Ethiopian Jews in Israel (p. 74). Wayne University State Press.

Weil, S. (2004). Ethiopian Jewish Women: Trends and transformations in the context of transnational change. Nashim: A Journal of Jewish Women's Studies and Gender Issues, 8, 73-83.

\section{Appendix — the Questionnaire (Note 1)}

Part A

(1) Gender: F/M

(2) Age:

(3) Country of Birth:

(4) Year of Immigration to Israel:

(5) What was the first language that you spoke?

(6) What other languages have you acquired?

(7) Which language do you speak at home?

(8) When you read a newspaper, what language is it written in?

Part B

Please rate your current ability in the four skills listed below in Amharic, Hebrew and English, according to the following scale:

1-Unable To;

2-With Difficulty;

3-Fair;

4-Good; 
5-Very Well.

Table 1. Self-Assessment of Language Competency

\begin{tabular}{llll}
\hline \multicolumn{1}{c}{ Skill } & Amharic & Hebrew & English \\
\hline Speaking & & & \\
Understanding & & & \\
Reading & & & \\
Writing & & & \\
\hline
\end{tabular}

\section{Part C}

Please mark: $\mathbf{X}$ for situations where you speak in Amharic

Please mark: $\mathbf{V}$ for situations where you speak in Hebrew

Please leave a blank for situations that are not relevant in your lives:

(1) In the supermarket, in a conversation with the cashier

(2) With my parents

(3) With my close friends

(4) With my co-workers

(5) With my brothers and sisters

(6) With my spouse at home

(7) With my spouse in a public place

(8) With my children at home

(9) With my children in a public place

(10) At my workplace

(11) Where I study

(12) In the bank

(13) With my distant relatives

(14) In my attempts to get information from customer service on the telephone

(15) With my childhood friends

(16) With my neighbors

(17) On the beach

Part D

Answer the questions:

(1) In your opinion, to what extent are the features of the ethnic background and the identity of the Ethiopian Jews shown in Israeli society (through its music, art, special holidays)?

(2) In your opinion, to what extent are the traditions and the culture of Ethiopian Jews thought of and shown in Israel?

(3) Write when you tend to speak in Amharic and when do you speak in Hebrew? 
(4) In your opinion, to what extent the English language useful to you in your lives?

(5) Write which language do your children speak with you at home? Outside the home?

(6) In your opinion, how important is it for you that your children speak Amharic with you? With your distant relatives?

(7) In your opinion, how important is it for you that your children speak Hebrew with you? With their friends?

(8) In your opinion, how important is it for you that your children speak English?

(9) In your opinion, even after living in Israel for many years, in what ways do you feel different from the Sabras?

(10) In your opinion, what are the obvious difference between the Ethiopian Jewish culture and the Israeli one?

(11) In your opinion, how can the Ethiopian Jewish culture improve the Israeli one?

(12) In your opinion, to what extent is preserving Amharic important for you?

(13) In your opinion, to what extent is preserving the Jewish Ethiopian culture in Israel important for you?

(14) In your opinion, how important is it for you to preserve your Jewish Amharic names?

(15) In your opinion, to what extent is the Jewish Ethiopian culture valued in the world, or in Jewish Ethiopian communities abroad?

\section{Note}

Note 1. The Questionnaire is based on Blustein (2006). 